\title{
Thermodynamic and Raman Spectroscopic Studies of Ar Hydrate System
}

\author{
Keisuke Sugahara, Ryuji Kaneko, Arata Sasatani, Takeshi Sugahara and Kazunari Ohgaki* \\ Division of Chemical Engineering, Graduate School of Engineering Science, Osaka University, 1-3, Machikaneyama, \\ Toyonaka, Osaka 560-8531, Japan
}

\begin{abstract}
The three-phase coexisting curve of Ar hydrate + water + gas has been investigated in a pressure range up to $485 \mathrm{MPa}$ and a temperature range of (279.57 to 305.32) K. The Raman spectrum of intermolecular O-O stretching vibration mode has been measured for Ar hydrate crystal along the stability boundary curve. Both the discontinuity of slope of the three-phase coexisting curve and the pressure dependence of the Raman shift reveal that two structural phase transition points exist at $(281 \pm 1) \mathrm{MPa}$ and $(302.7 \pm 0.1) \mathrm{K},(456 \pm 1) \mathrm{MPa}$ and $(304.6 \pm 0.1) \mathrm{K}$ in a pressure range up to $485 \mathrm{MPa}$ for the Ar hydrate system.
\end{abstract}

\section{INTRODUCTION}

Ar hydrate was found out by Villard in 1896 [1], and it has been widely studied by many investigators. It is well known that Ar hydrate belongs to structure-II hydrate [2] as well as $\mathrm{Kr}, \mathrm{O}_{2}$, and $\mathrm{N}_{2}$ hydrates. Structure-II hydrate is composed of the two types of hydrogen-bonded water cages. We have called S-cage (pentagonal dodecahedron, $5^{12}$ ) and Lcage (hexakaidecahedron, $5^{12} 6^{4}$ ), and its crystal type is cubic (Fd3m).

Thermodynamic stability boundary for the Ar hydrate system at high pressures has been reported by several investigators. Dyadin, Larionov, Mirinski, Mikina, and Starostina [3] have reported the stability boundary of hydrate formation in the $\mathrm{Ar}-\mathrm{H}_{2} \mathrm{O}$ system under pressure up to $1500 \mathrm{MPa}$. They have indicated that two structural transition points are located at $720 \mathrm{MPa}$ and $960 \mathrm{MPa}$. Lotz and Schouten [4] have claimed that structure-II Ar hydrate changes to structure-I around $620 \mathrm{MPa}$ from the decomposition curve originated from new quadruple point (620 MPa and 304.6 K). Manakov, Voronin, Kurnosov, Teplykh, Larionov, and Dyadin [5] measured the stability boundary in a pressure range up to $1000 \mathrm{MPa}$. They have claimed that there are three structural phase transition points from the discontinuity of $\mathrm{d} p / \mathrm{d} T$ on the stability boundary, and discovered that the structure-II Ar hydrate changes to the structure- $\mathrm{H}$ type hydrate $(\mathrm{P} 6 / \mathrm{mmm})$ at $460 \mathrm{MPa}$, which is similar to the low-pressure's one discovered by Ripmeester, Tse, Ratcliffe, and Powell [6]; the structure-H is composed of three $\mathrm{S}$-cages, two $\mathrm{S}^{\prime}$-cages $\left(4^{3} 5^{6} 6^{3}\right)$, and one U-cage $\left(5^{12} 6^{8}\right)$. The most important finding by Kurnosov, Manakov, Komarov, Voronin, Teplykh, and Dyadin [7] is that the tetragonal hydrate structure $\left(P 4_{2} / \mathrm{mmm}\right)$ consists of two 14-hedral cavities $\left(4^{2} 5^{8} 6^{4}\right)$ in the unit lattice and two Ar atoms occupy a 14-hedral cavity in a pressure range of (770 to 960) $\mathrm{MPa}$. Hirai, Uchihara, Nishimura, Kawamura, Yoshimoto, and Yagi [8] confirmed the tetragonal structure by $\mathrm{X}$-ray diffraction studies at room tempera

*Address correspondence to this author at the Division of Chemical Engineering, Graduate School of Engineering Science, Osaka University, 1-3, Machikaneyama, Toyonaka, Osaka 560-8531, Japan; Fax: +81-6-68506290; E-mail: ohgaki@cheng.es.osaka-u.ac.jp ture, but they couldn't find structure-H Ar hydrate around $500 \mathrm{MPa}$. Loveday, Nelmes, Klug, Tse, and Desgreniers [9] support those findings of Manakov, Voronin, Kurnosov, Teplykh, Larionov, and Dyadin [5] and Kurnosov, Manakov, Komarov, Voronin, Teplykh, and Dyadin [7], and they clarify that the Ar hydrate changes to so called "filled-ice" above $960 \mathrm{MPa}$.

Shimizu, Hori, Kume, and Sasaki [10] have reported that the Raman spectra of interatomic Ar-Ar interaction are detected around $150 \mathrm{~cm}^{-1}$ in the pressure range from (160 to 970) $\mathrm{MPa}$ at room temperature. They have claimed that this Raman spectrum corresponds to the multioccupancy of $\mathrm{Ar}$ atoms in the L-cage of structure-II. The double occupancy of Ar hydrate system has been predicted by many simulation approaches [11-13]. Based on the neutron diffraction experiments at $293 \mathrm{~K}$, Manakov, Voronin, Kurnosov, Teplykh, Komarov, and Dyadin [14] have reported the multioccupancy of the structure-II Ar hydrate in the pressure range from (340 to 430) MPa.

Many investigators have studied the Ar hydrate system, but the most of them have carried out by use of Diamond Anvil Cell at room temperature, which is away from threephase coexisting conditions (hydrate + water + gas). Unless the investigation is carried out along the three-phase coexisting condition, any varied structure might emerge depending on the composition. We have already reported other two noble gas hydrate systems ( $\mathrm{Kr}$ and $\mathrm{Xe}$ ) in the pressure range up to approximately $500 \mathrm{MPa}$ under three-phase coexisting conditions [15]. Based on the slope change of the boundary curve and the pressure dependence on the Raman O-O shifts for the $\mathrm{Kr}$ hydrate crystal, a structural phase transition point exists at $414 \mathrm{MPa}$ and $319.20 \mathrm{~K}$, while the Xe hydrate crystal of structure-I does not exhibit any phase transition in the pressure range up to $500 \mathrm{MPa}$. In the present study, the three-phase coexisting curve (hydrate + water + gas) for Ar hydrate system in a temperature range of (279.57 to 305.32) $\mathrm{K}$ and a pressure range up to $485 \mathrm{MPa}$ has been investigated precisely. The pressure dependence of the intermolecular O$\mathrm{O}$ vibration along the three-phase coexisting curve has been analyzed by use of laser Raman spectroscopy. 


\section{EXPERIMENTAL SECTION}

\section{Materials}

Research grade Ar was purchased from the Neriki Gas Co. Ltd., having a stated minimum purity of $99.9999 \mathrm{~mol} \%$. Distilled water was obtained from Yashima Pure Chemicals Co. Ltd. Both were used without further purification.

\section{Experimental Apparatus}

Two types of high-pressure cell that are appropriate for the experimental pressure region were used in the present study. The experimental apparatus were essentially the same as that used previously [16, 17]. It consisted of a highpressure cell having a couple of sapphire windows (inner volume, $1 \mathrm{~cm}^{3}$ and $0.2 \mathrm{~cm}^{3}$; maximum working pressure was $75 \mathrm{MPa}$ and $500 \mathrm{MPa}$, respectively; Both were made of stainless steel, SUS630), a mixing ball, a high-pressure pump for supplying and/or pressurizing the samples, an intensifier, pressure gauges, a temperature control system, and, a charge-coupled device (CCD) camera. The high-pressure cell (500 MPa) was designed and manufactured to establish the equilibrium conditions for measuring the three-phase coexisting curve and to prepare the hydrate single crystal for performing in situ laser Raman spectroscopic analysis, simultaneously.

\section{Procedures}

A desired amount of Ar was introduced into the evacuated and cooled cell. A mixing ball in the cell was vibrated from the outside for agitation. The contents were pressurized up to the desired pressure by successive supply of water. After the formation of Ar hydrate, in order to establish the three-phase (hydrate + water + gas) equilibrium, the system temperature was gradually increased and the contents were agitated intermittently. The phase behavior of the system was observed by the CCD camera through the sapphire window. The equilibrium temperature was measured within a reproducibility of $0.02 \mathrm{~K}$ using a thermistor probe (Takara D-641) calibrated by a Pt resistance thermometer $(25 \Omega)$ into the water bath or a hole in the cell wall. For pressure measurement, two different pressure gauges were used according the working pressure. Up to $75 \mathrm{MPa}$, a pressure gauge (Valcom VPRT) calibrated by a Ruska quartz Bourdon tube gauge was used with an estimated maximum uncertainty of $0.02 \mathrm{MPa}$. Over $75 \mathrm{MPa}$, a pressure transducer (NMB STD$5000 \mathrm{~K}$ ) and digital peak holder (NMB CSD-819) was used with an estimated maximum uncertainty of $2 \mathrm{MPa}$.

After the preparation of single crystal at the three-phase coexisting equilibrium under several pressure conditions, the Raman spectra were measured. A typical photograph of Ar hydrate crystals is shown in Fig. (1). The largest single crystal (the preparation procedures were described elsewhere [17]) was aged more than a couple of weeks. In several equilibrium conditions, Ar hydrate crystals were analyzed using a laser Raman microprobe spectrometer with a multichannel CCD detector (Jobin Yvon Ramanor T64000). The laser beam from the object lens irradiated the sample through the upper sapphire window. The backscatter of the opposite direction was taken in with the same lens. The argon ion laser beam of $514.5 \mathrm{~nm}$ and $100 \mathrm{~mW}$ was condensed to $2 \mu \mathrm{m}$ spot diameter. The spectral resolution was about $1 \mathrm{~cm}^{-1}$.

\section{RESULTS AND DISCUSSION}

The three-phase coexisting data obtained in the present study for the Ar hydrate system are listed in Table 1. Fig. (2) shows the pressure temperature relations of Ar hydrate system accompanied with the literature values $[3,18]$. In the low-pressure region (up to $200 \mathrm{MPa}$ ), our data are in good agreement with Marshall's ones [18]. Moreover, except less than $20 \mathrm{MPa}$, the present data are in almost agreement with Dyadin's ones [3].
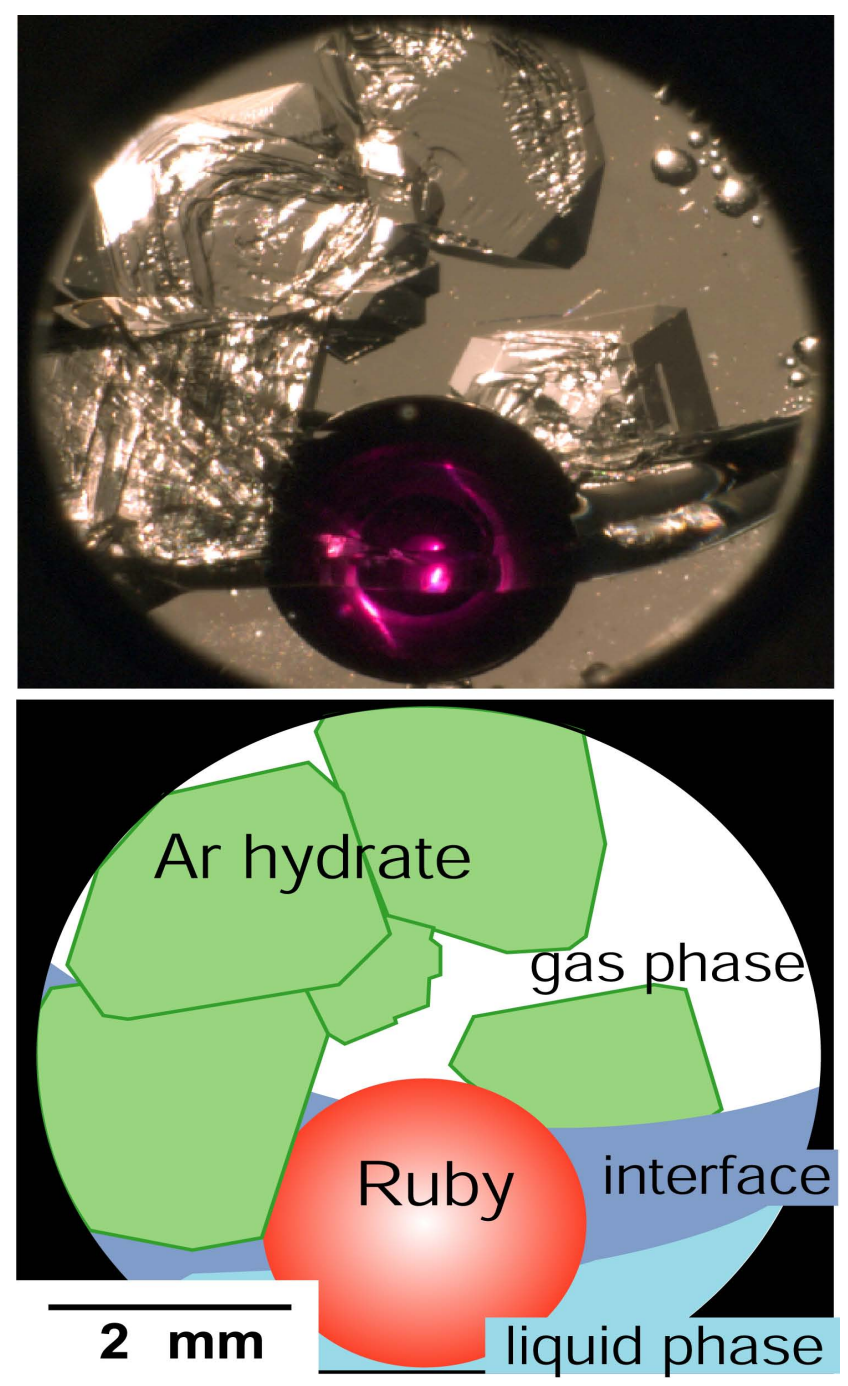

Fig. (1). Photo (upper) and schematic drawing (bottom) of single crystals of Ar hydrate under three-phase coexisting condition of hydrate + liquid (water) + gas at $284 \mathrm{MPa}$ and $302.75 \mathrm{~K}$. A spherical ruby of $2.5 \mathrm{~mm}$ in diameter is trapped in the high-pressure cell in order to stir the contents.

Fig. (3) shows the extended figure (the pressure ranges from $200 \mathrm{MPa}$ to $500 \mathrm{MPa}$ ) of the thermodynamic stability boundary for the Ar hydrate system in the present study. The stability boundary changes greatly in the slope at $(281 \pm 1)$ $\mathrm{MPa}$ and $(302.7 \pm 0.1) \mathrm{K}$, and $(456 \pm 1) \mathrm{MPa}$ and $(304.6 \pm 0.1$ $\mathrm{K})$ respectively. Generally, the large slope change of $\mathrm{d} p / \mathrm{d} T$ means the structural phase transition point as previously described $[15,19]$ ( $\mathrm{Kr}$ and $\mathrm{SF}_{6}$ hydrate systems). Manakov, Voronin, Kurnosov, Teplykh, Larionov, and Dyadin [5] have reported the structural change (structure-II to structure-H) 
around $460 \mathrm{MPa}$. On the other hand, no investigator has reported about the structural change point around $280 \mathrm{MPa}$. We have divided the three-phase coexisting curve to the three regions. The region A corresponds to the pressure range up to $281 \mathrm{MPa}$. The pressure range from 281 to 456 $\mathrm{MPa}$ is region $\mathrm{B}$, and over $456 \mathrm{MPa}$ defined as region $\mathrm{C}$. Especially, in the region B, the present data show the large discrepancies with the literature [3, 18].

Table 1. Three-Phase Coexisting Data for the Ar Hydrate System

\begin{tabular}{|c|c|c|c|}
\hline $\boldsymbol{T} / \mathbf{K}$ & $\boldsymbol{p} / \mathbf{M P a}$ & $\boldsymbol{T} / \mathbf{K}$ & $\boldsymbol{p} / \mathbf{M P a}$ \\
\hline \hline 279.57 & 17.72 & 293.95 & 98 \\
\hline 280.55 & 19.81 & 294.70 & 108 \\
\hline 281.64 & 22.23 & 296.10 & 129 \\
\hline 282.64 & 24.44 & 297.17 & 147 \\
\hline 283.95 & 28.17 & 297.99 & 169 \\
\hline 284.72 & 31.93 & 299.44 & 199 \\
\hline 284.84 & 32.38 & 300.39 & 226 \\
\hline 285.25 & 32.60 & 301.65 & 258 \\
\hline 286.15 & 38.29 & 302.75 & $284(\mathrm{~s}-\mathrm{I})$ \\
\hline 287.16 & 42.86 & 303.09 & $322(\mathrm{~s}-\mathrm{I})$ \\
\hline 288.16 & 48.82 & 303.60 & $358(\mathrm{~s}-\mathrm{I})$ \\
\hline 288.66 & 51.70 & 304.10 & $409(\mathrm{~s}-\mathrm{I})$ \\
\hline 289.65 & 57.96 & 304.57 & $447(\mathrm{~s}-\mathrm{I})$ \\
\hline 290.68 & 66.22 & 305.05 & $464(\mathrm{~s}-\mathrm{H})$ \\
\hline 291.06 & 69.40 & 305.19 & $474(\mathrm{~s}-\mathrm{H})$ \\
\hline 292.07 & 77 & 305.21 & $476(\mathrm{~s}-\mathrm{H})$ \\
\hline 293.18 & 89 & 305.32 & $485(\mathrm{~s}-\mathrm{H})$ \\
\hline
\end{tabular}

(s-I), structure-I; (s-H), structure-H.

The Raman spectrum of intermolecular O-O stretching vibration mode of water molecules was detected around 210 $\mathrm{cm}^{-1}$ in the structure-II gas hydrate systems; we have already reported about $\mathrm{N}_{2}$ and $\mathrm{SF}_{6}$ hydrate systems $[19,20]$. The peak corresponding to the hydrate cage structured by hydrogen bonds is a peculiar to the structure of hydrate lattice. In the present study, the Raman shift of the O-O stretching vibration for the Ar hydrate crystal at $46 \mathrm{MPa}$ and $288 \mathrm{~K}$ is detected at $209 \mathrm{~cm}^{-1}$. The typical Raman spectra of the intermolecular $\mathrm{O}-\mathrm{O}$ vibration mode in the Ar hydrate crystals in each region of Fig. (3) are shown in Fig. (4). The O-O vibration energy increases with pressure (along the threephase coexisting curve), that is, the hydrate cage shrinks gradually by pressurization.

Fig. (5) shows the pressure dependence of the Raman shift corresponding to the O-O stretching vibration for the Ar hydrate system, which measured along the three-phase coexisting curve. For comparison, the previous results of the $\mathrm{Kr}$ (structure-II) and Xe (structure-I) hydrate crystals measured along the three-phase coexisting curves [15] are also shown in Fig. (5). We have already speculated that the structure-II
$\mathrm{Kr}$ hydrate changes to structure- $\mathrm{H}$ at $414 \mathrm{MPa}$ by the slope change of three-phase coexisting curve and the Raman spectrum.

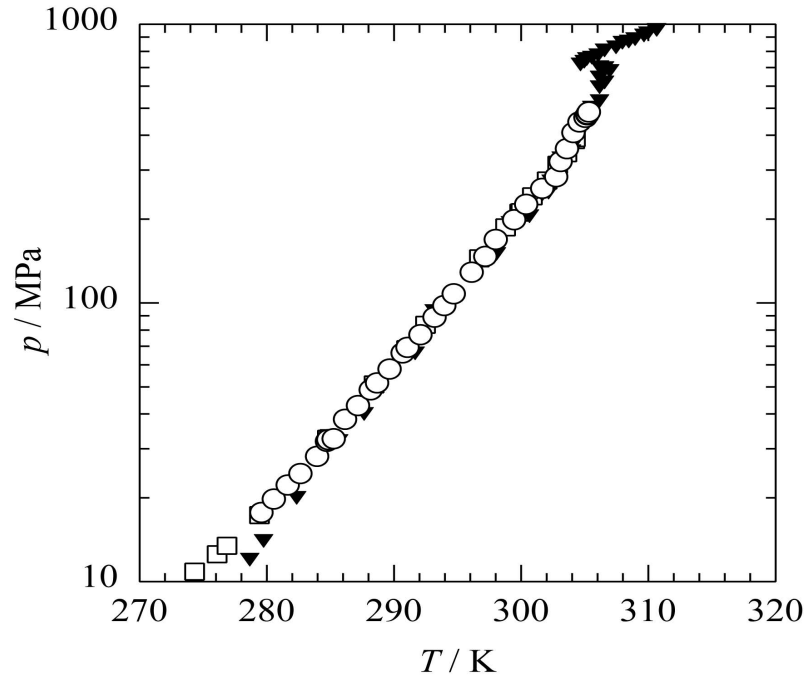

Fig. (2). Pressure - temperature relations of Ar hydrate stability boundaries: $\bigcirc$, three-phase coexisting curve of Ar hydrate (present study); $\square$, Marshall, Saito, and Kobayashi [18]; $\nabla$, Dyadin, Larionov, Mirinski, Mikina, and Starostina [3]. From our experimental data (up to $485 \mathrm{MPa}$ ), Ar hydrate has two structural transition points located at $281 \mathrm{MPa}$ and $456 \mathrm{MPa}$. Dyadin, Larionov, Mirinski, Mikina, and Starostina [3] have claimed that the discontinuous slope changes around $460 \mathrm{MPa}$ and $770 \mathrm{MPa}$ are caused by structural transitions to structure- $\mathrm{H}$ [5] and to tetragonal structure [7], respectively.

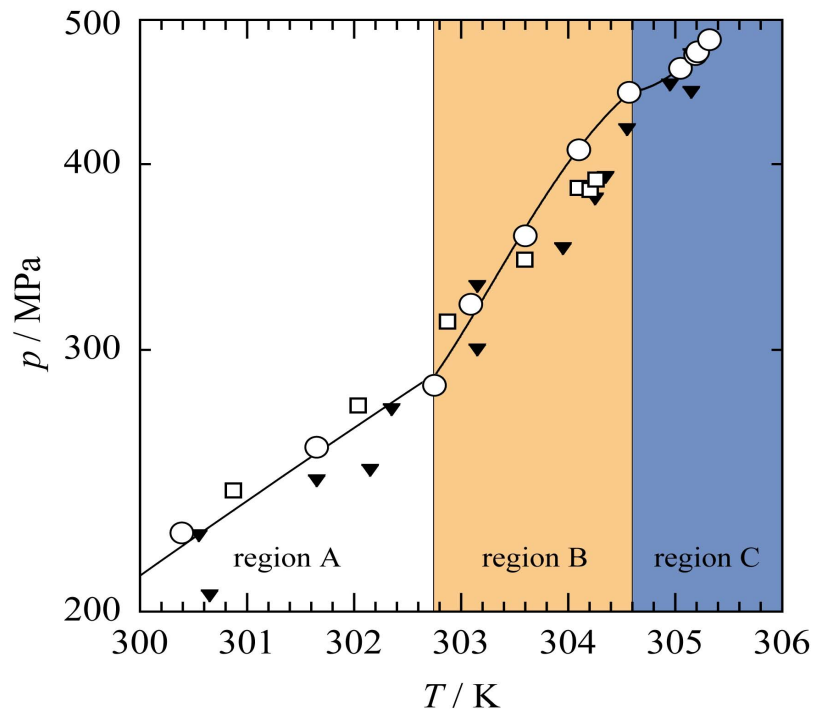

Fig. (3). Enlarger data (the pressure ranges from $200 \mathrm{MPa}$ to 500 MPa) of Fig. 2: ○, present study; $\square$, Marshall, Saito, and Kobayashi [18]; $\boldsymbol{\nabla}$, Dyadin, Larionov, Mirinski, Mikina, and Starostina [3]. The stable structure in each region is as follows; region A, structure-II; region B, structure-I; region $\mathrm{C}$, structure-H.

The pressure dependence of the O-O vibration in the $\mathrm{Ar}$ hydrate system up to $281 \mathrm{MPa}$ (correspond to region A of Fig. (3)) agrees well with the structure-II Kr hydrate system. Therefore, the structure-II Ar hydrate is stable in the region A. 


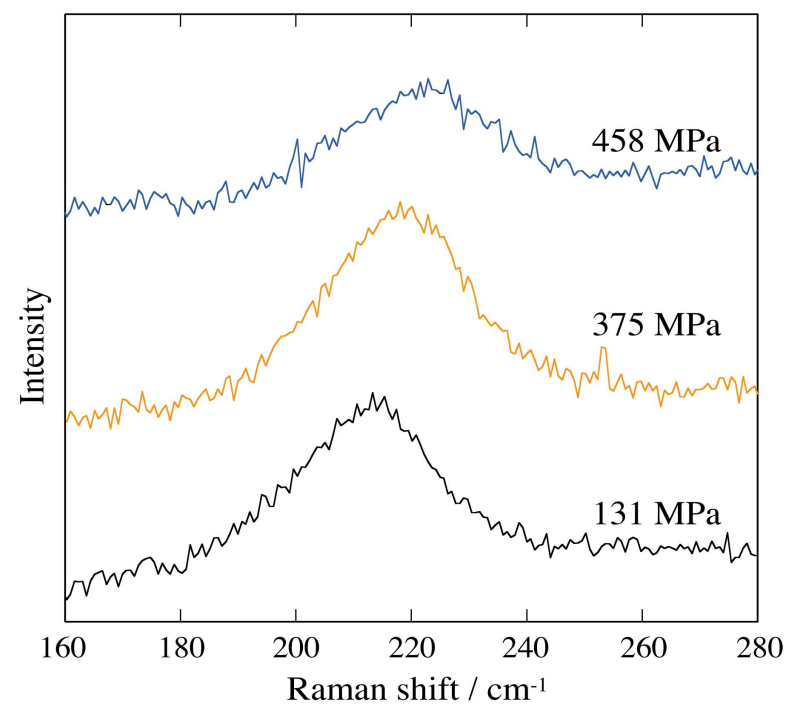

Fig. (4). Raman spectra of the intermolecular O-O vibration mode in the Ar hydrate crystals at $131 \mathrm{MPa}$ (structure-II), $375 \mathrm{MPa}$ (structure-I), and $458 \mathrm{MPa}$ (structure-H).

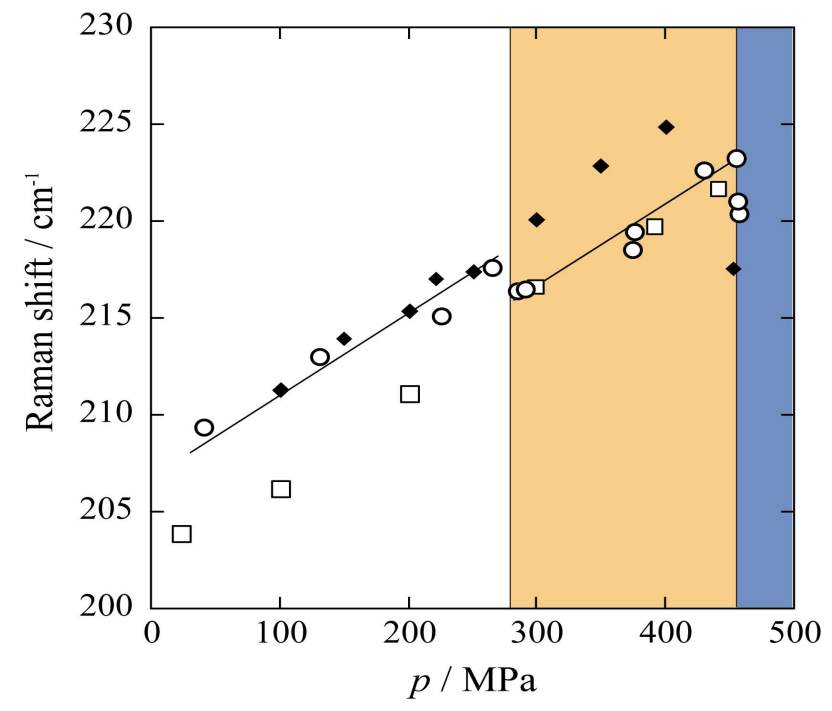

Fig. (5). Pressure dependence of the Raman shift corresponding to the O-O stretching vibration for the Ar hydrate system along the three-phase coexisting curve: $\bigcirc$, Ar hydrate; $\bullet, \mathrm{Kr}$ hydrate (structure-II: up to $414 \mathrm{MPa}$; structure-H: over $414 \mathrm{MPa}$ ) [15] ; $\square, \mathrm{Xe}$ hydrate (structure-I) [15].

From the pressure range from (281 to 456) MPa (correspond to region $\mathrm{B}$ ), the results of the $\mathrm{O}-\mathrm{O}$ vibration are almost same tendency of the Xe hydrate system [15]. The fact suggests that Ar hydrate crystal may be the structure-I lattice in the region $\mathrm{B}$. Moreover, the slope change of the stability boundary (Fig. (3)) also supports structural phase transition of Ar hydrate crystal. However, Shimizu, Hori, Kume, and Sasaki [10] have evaluated the multi occupancy of Ar atoms by the Raman spectra of Ar-Ar interatomic stretching vibration around $150 \mathrm{~cm}^{-1}$. Manakov, Voronin, Kurnosov, Teplykh, Komarov, and Dyadin [14] have suggested the double occupancy of the structure-II Ar hydrate in the pressure region from (340 to 440) MPa based on neutron diffraction experiments at $293 \mathrm{~K}$. Tanaka, Nakatsuka, and Koga [11] reported that double occupancy dominated over single occu- pancy above $270 \mathrm{MPa}$ from van der Walls Platteuw theory. In the present study, those were not taken up because it was difficult to clarify the meaning Raman peak from noises on the shoulder of Rayleigh scattering. Therefore, we cannot discuss about the double occupancy of Ar atoms in the $\mathrm{Ar}$ hydrate system by the Raman peaks of the present study. On the other hand, Lotz and Schouten [4] suggested that structure-II Ar hydrate changes to structure-I at the high-pressure region. Thus, it might be thought that there are the following two possibilities about the phenomenon around $280 \mathrm{MPa}$; the structural phase transition of Ar hydrate and/or the change of cage occupancy. We speculate as follows. Around $280 \mathrm{MPa}$, the one Ar atom occupied in the one large cage (M-cage) of structure-I may be more comfortable than two Ar atoms occupied in the one L-cage (double occupancy) of structure-II. And as a result, the structural change from structure-II Ar hydrate to structure-I has occurred in the region $\mathrm{B}$.

At $459 \mathrm{MPa}$ (correspond to region $\mathrm{C}$ ), the $\mathrm{O}-\mathrm{O}$ vibration energy of Ar hydrate becomes lower than that of structure-I hydrate [15] (Xe hydrate system). The similar discontinuity of the pressure dependence has shown in the Kr hydrate system (Fig. (5)); the Raman shift of Ar hydrate is slightly (3 $\mathrm{cm}^{-1}$ ) higher than that of the Kr hydrate at almost same pressure; in this pressure range, the $\mathrm{Kr}$ hydrate is structure- $\mathrm{H}$ [15]. Moreover, there is a drastic slope change of three-phase coexisting curve of Ar hydrate around $456 \mathrm{MPa}$ in the present study (Fig. (3)). They show good agreement with Manakov, Voronin, Kurnosov, Teplykh, Larionov, and Dyadin [5] (460 MPa). Those facts strongly support that the structural phase transition in the Ar hydrate crystal occurs around $456 \mathrm{MPa}$, and that the structure of Ar hydrate observed over $456 \mathrm{MPa}$ (region $\mathrm{C}$ ) would be structure- $\mathrm{H}$ as reported by Manakov, Voronin, Kurnosov, Teplykh, Larionov, and Dyadin [5] and Manakov, V. I. Voronin, A. V. Kurunosov, A. E. Teplykh, V. Y. Komarov, and Y. A. Dyadin [14] and Loveday, Nelmes, Klug, Tse, and Desgreniers [9]. Additionally, in the high-pressure region (760 to $960 \mathrm{MPa}$ ), the tetragonal Ar hydrate would be stable as Kurnosov, Manakov, Komarov, Voronin, Teplykh, and Dyadin [7] have reported.

\section{CONCLUSIONS}

The three-phase coexisting curve of Ar hydrate system was obtained up to $485 \mathrm{MPa}$. Single crystals of Ar hydrate were analyzed in situ by use of laser Raman spectroscopy along the three-phase coexisting curve. The slope changes of $\mathrm{d} p / \mathrm{d} T$ on the boundary curve and the pressure dependence of the intermolecular O-O stretching vibration mode of the $\mathrm{Ar}$ hydrate system reveal that two structural phase transition points exist at $(281 \pm 1) \mathrm{MPa}$ and $(302.7 \pm 0.1) \mathrm{K}$, (456 \pm 1$)$ $\mathrm{MPa}$ and $(304.6 \pm 0.1) \mathrm{K}$, respectively. For the Ar hydrate system, the structure-II hydrate crystal exists up to $281 \mathrm{MPa}$ and changes to structure-I in the pressure region from 281 to $456 \mathrm{MPa}$. Finally, Ar hydrate changes to structure-H around $456 \mathrm{MPa}$.

\section{ACKNOWLEDGEMENTS}

The authors are grateful to the Division of Chemical Engineering, Graduate School of Engineering Science, Osaka University for the scientific support by "Gas-Hydrate Analyzing System (GHAS)." 


\section{REFERENCES}

[1] P. Villard, "Combination de l'argon avec l'eau", Comptes Rendus Hebdomadaires des Seances de l'Academie des Sciences., vol. 123, pp. 377-380, July 1896.

[2] D. W. Davidson, Y. P. Handa, C. I. Ratcliffe, J. S. Tse, and B. M. Powell, "The ability of small molecules to form clathrate hydrates of structure II", Nature, vol. 311, pp. 142-143, Sep. 1984.

[3] Y. A. Dyadin, E. G. Larionov, D. S. Mirinski, T. V. Mikina, and L. I. Starostina, "Clathrate formation in the $\mathrm{Ar}-\mathrm{H}_{2} \mathrm{O}$ systems under pressures up to 15000 bar", Mendeleev Commun., vol. 7, pp. 33-34, Jan.-Feb. 1997.

[4] H. T. Lotz and J. A. Schouten, "Clathrate Hydrate in the System $\mathrm{H}_{2} \mathrm{O}-\mathrm{Ar}$ at pressures and temperatures up to $30 \mathrm{kbar}$ and $140{ }^{\circ} \mathrm{C}$ ", $J$. Chem. Phys., vol. 111, pp. 10242-10247, Dec. 1999.

[5] A. Y. Manakov, A. V. Voronin, A. V. Kurnosov, A. E. Teplykh, E. G. Larionov, and Y. A. Dyadin, "Argon Hydrates: structural studies at high pressures", Doklady Phys. Chem., vol. 378, pp. 148-151, June 2001

[6] J. A. Ripmeester, J. S. Tse, C. I. Ratcliffe, and B. M. Powell, "A new clathrate hydrate structure", Nature, vol. 325, pp. 135-136, Jan. 1987.

[7] A. V. Kurnosov, A. Y. Manakov, V. Y. Komarov, V. I. Voronin, A. E. Teplykh, and Y. A. Dyadin, "A new gas hydrate structure", Doklady Phys. Chem., vol. 381, pp. 303-305, Dec. 2001.

[8] H. Hirai, Y. Uchihara, Y. Nishimura, T. Kawamura, Y. Yoshimoto, and T. Yagi, "Structural changes of Argon hydrate under high pressure", J. Phys. Chem. B, vol. 106, pp. 11089-11092, Oct. 2002.

[9] J. S. Loveday, R. J. Nelmes, D. D. Klug, J. S. Tse, and S. Desgreniers, "Structural systematics in the clathrate hydrates under pressure", Can. J. Phys., vol. 81, pp. 539-544, Jan.-Feb. 2003.

[10] H. Shimizu, S. Hori, T. Kume, and S. Sasaki, "Optical microscopy and raman scattering of a single crystalline argon hydrate at high pressures", Chem. Phys. Lett., vol. 368, pp. 132-138, Jan. 2003.
[11] H. Tanaka, T. Nakatsuka, and K. Koga, "On the thermodynamic stability of clathrate hydrates IV: double occupancy of cages", $J$. Chem. Phys., vol. 121, pp.5488-5493, Sep. 2004.

[12] T. M. Inerbaev, V. R. Belosludov, R. V. Belosludov, M. Sluiter, Y. Kawazoe, and J. Kudoh, "Theoretical study of clathrate hydrates with multiple occupation", J. Inclusion Phenom Macrocycl Chem., vol. 48, pp. 55-60, Feb. 2004.

[13] G. G. Malenkov, and E. A. Zheligovskaya, "Dynamics of Some He and Ar clathrate hydrates. Computer Simulation Study", J. Inclusion Phenom Macrocycl. Chem., vol. 48, pp. 45-54, Feb. 2004.

[14] A. Y. Manakov, V. I. Voronin, A. V. Kurnosov, A. E. Teplykh, V. Y. Komarov, and Y. A. Dyadin, "Structural investigations of argon hydrates at pressure up to $10 \mathrm{kbar}$ ", J. Inclusion Phenom. Macrocycl. Chem., vol. 48, pp. 11-18, Feb. 2004

[15] K. Sugahara, T. Sugahara, and K. Ohgaki, "Thermodynamic and Raman Spectroscopic Studies on Xe and Kr Hydrates", J. Chem. Eng. Data, vol. 50, pp. 274-277, Jan. 2005.

[16] K. Ohgaki, and T. Hamanaka, "Phase-behavior of $\mathrm{CO}_{2}$ hydrateliquid $\mathrm{CO}_{2}-\mathrm{H}_{2} \mathrm{O}$ system at high pressure", Kagaku Kougaku Ronbunshu, vol. 21, pp. 800-803, July 1995.

[17] S. Nakano, M. Moritoki, and K. Ohgaki, "High-pressure phase equilibrium and raman microprobe spectroscopic studies on the $\mathrm{CO}_{2}$ hydrate system", J. Chem. Eng. Data, vol. 43, pp. 807-810, Sep. 1998.

[18] D. R. Marshall, S. Saito, and R. Kobayashi, "Hydrates at high pressures: Part I. Methane-Water, Argon-Water, and NitrogenWater Systems", Am. Inst. Chem. Eng. J., vol. 10, pp. 202-205, Mar. 1964.

[19] K. Sugahara, M. Yoshida, T. Sugahara, and K. Ohgaki, "Thermodynamic and raman spectroscopic studies on pressure-induced structural transition of $\mathrm{SF}_{6}$ hydrate", J. Chem. Eng. Data, vol. 51, pp. 301-304, Jan. 2006.

[20] K. Sugahara, Y. Tanaka, T. Sugahara, and K. Ohgaki, "Thermodynamic stability and structure of nitrogen hydrate crystal", $J$. Supramol. Chem., vol. 2, pp. 365-368, Aug.-Oct. 2002.

(c) Sugahara et al.; Licensee Bentham Open.

This is an open access article licensed under the terms of the Creative Commons Attribution Non-Commercial License (http://creativecommons.org/licenses/by$\mathrm{nc} / 3.0 /$ ) which permits unrestricted, non-commercial use, distribution and reproduction in any medium, provided the work is properly cited. 